\title{
Bone morphogenetic protein 7 in the treatment of congenital pseudarthrosis of the tibia
}
L. Fabeck,
D. Ghafil,
M. Gerroudj,
R. Baillon,
Ph. Delincé

From CHU Saint

Pierre, Brussels, Belgium

L. Fabeck, MD, PhD, Orthopaedic Surgeon, Professor

D. Ghafil, MD, Orthopaedic Surgeon

In. Merroudj, MD, General

Practitioner

R. Baillon, MD,

Orthopaedic Surgeon

Ph. Delincé, MD

Orthopaedic Surgeon,

Professor

Department of Orthopaedic Surgery

CHU Saint Pierre, 322 rue Haute, 1000 Brussels,

Belgium.

Correspondence should be sent to Dr L. Fabeck; e-mail: laurent_fabeck@ stpierre-bru.be

(C)2006 British Editorial Society of Bone and Joint Surgery doi:10.1302/0301-620X.88B1. $16619 \$ 2.00$

$J$ Bone Joint Surg $[\mathrm{Br}]$ 2006;88-B:116-18.

Received 15 April 2005; Accepted after revision 6 September 2005

\begin{abstract}
We describe a 13-year-old boy with atrophic tibial pseudarthrosis associated with neurofibromatosis who had undergone nine unsuccessful operations. Eventually, union was obtained by the use of bone morphogenetic protein 7 in conjunction with intramedullary stabilisation and autologous bone graft.
\end{abstract}

Congenital pseudarthrosis of the tibia is a rare disorder, usually appearing during the first two years of life. Neurofibromatosis is present in approximately $40 \%$ to $50 \%$ of patients with pseudarthrosis and approximately $10 \%$ of patients with neurofibromatosis develop pseudarthrosis of the tibia. Treatment is challenging and often disappointing and unsatisfactory outcomes may lead to amputation. ${ }^{1}$

Operative treatment includes intramedullary rodding and grafting, limb lengthening, vascularised fibular transfer and the Ilizarov techniques. ${ }^{2-5}$ However, even after multiple attempts to achieve bony union, ${ }^{2-4}$ amputation may be needed.

The osteogenic proteins are a class of natural growth factors of the bone morphogenetic pro- tein family (BMP) which stimulate bone regeneration. ${ }^{6} \mathrm{~A}$ specific member of this family is BMP7 , known as human recombinant osteogenic protein number 1 (rh OP-1), which accelerates bone repair compared with a control fracture when injected into a fresh fracture model. ${ }^{7}$

\section{Case report}

The patient was born by normal delivery after an uneventful pregnancy. There was no family history of congenital problems. At the age of nine months, 'café-au-lait spots' appeared on his back and abdomen. At 14 months, there was anterior bowing of the right leg and neurofibromatosis was diagnosed. When he had reached 20 months and began to walk, the leg was protected by an ankle-foot orthosis with an anterior shell.

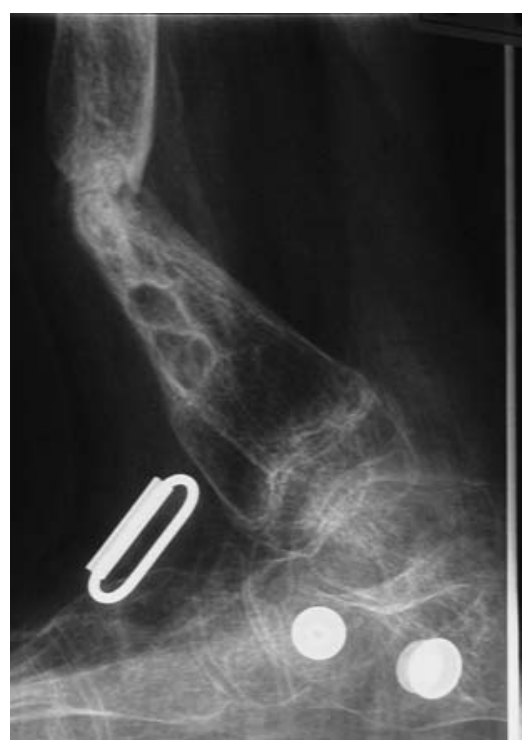

Fig. 1a

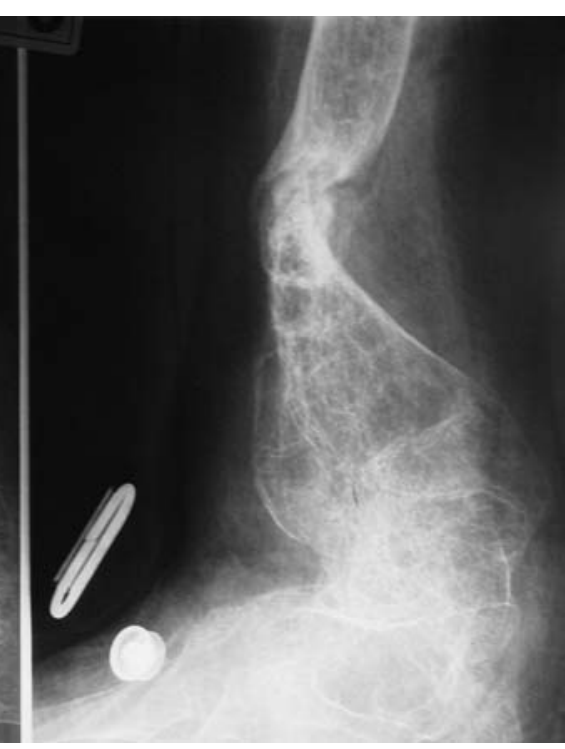

Fig. $1 \mathrm{~b}$
Radiographs showing the tibia pre-operatively a) lateral and b) anteroposterior views. The boy had undergone nine unsuccessful surgical treatments. 


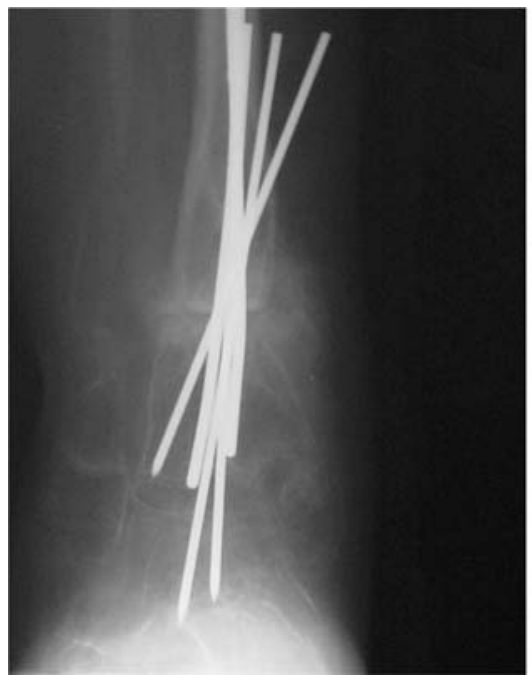

Fig. 2a

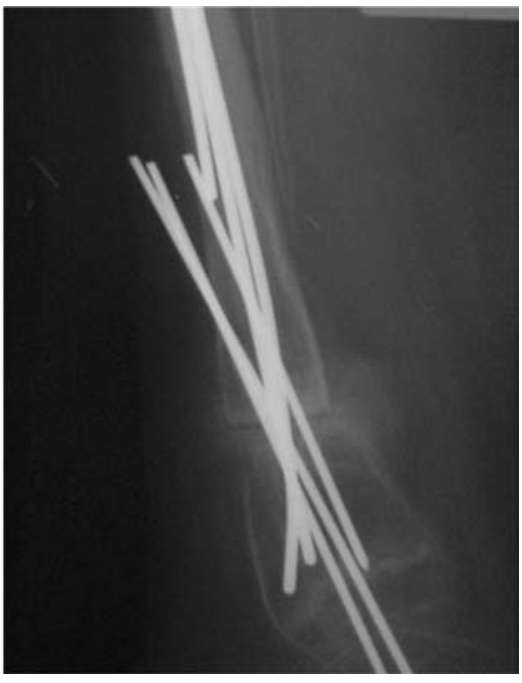

Fig. 2b
Radiographs showing early bony union five weeks after surgery a) anteroposterior and b) lateral views.

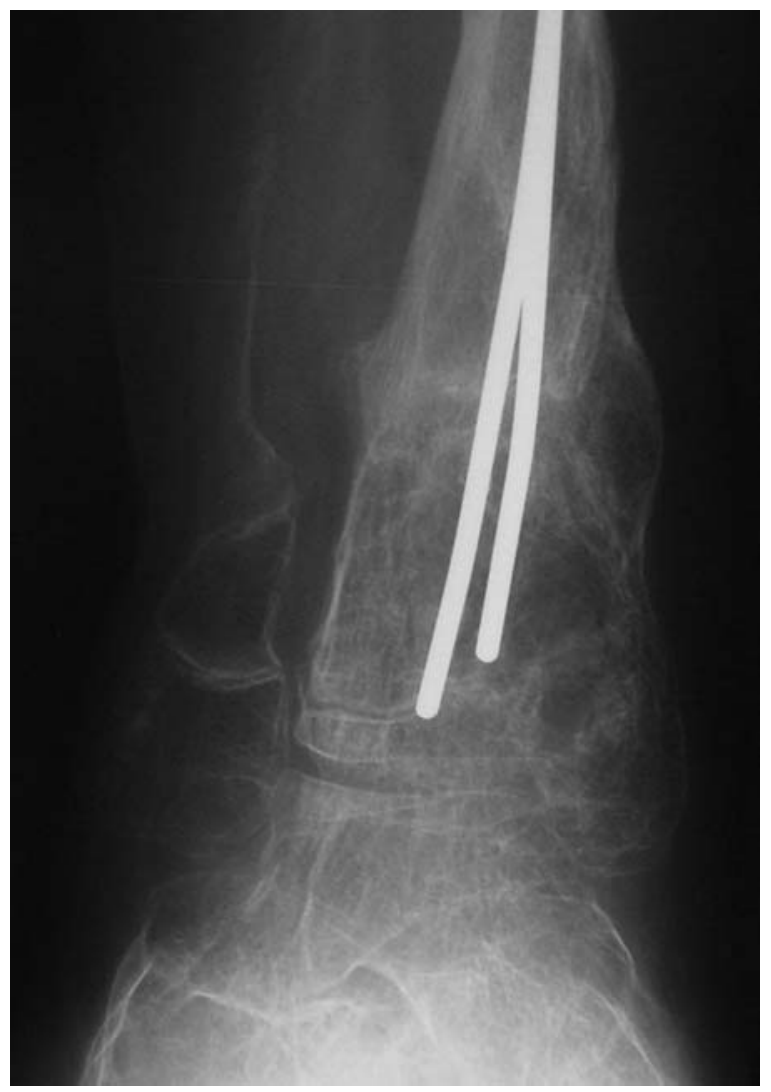

Fig. 3

Radiograph at five months post-operatively following removal of the transarticular pins.

At 30 months, he fell and fractured his tibia and fibula in the region of the deformity. After six months of unsuccessful cast treatment, he underwent intramedullary nailing. Five subsequent operations, combining intramedullary nailing with autograft and casting, were unsuccessful. Each

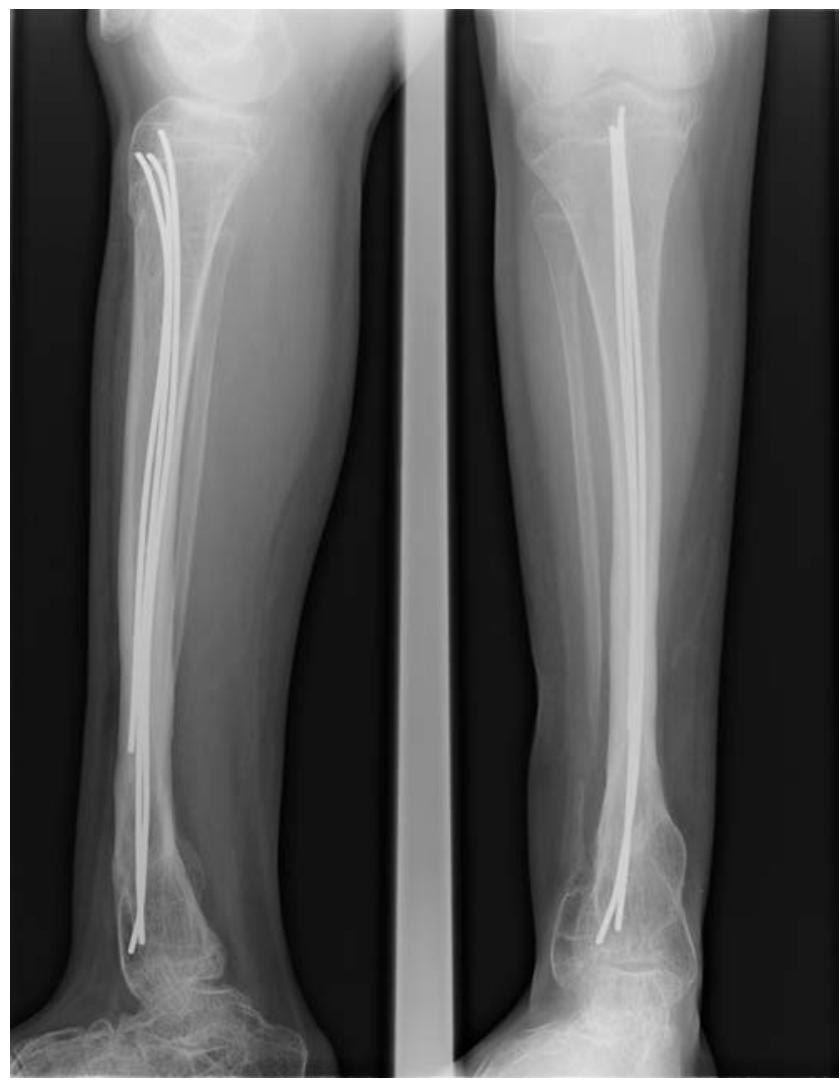

Fig. 4

Radiographs showing the fracture is united two years after surgery.

time after the protective cast or the intramedullary rods were removed, the leg refractured.

When he was eight years old, the Ilizarov technique was tried for a period of seven months during which several pintrack infections required treatment with antibiotics. Union 


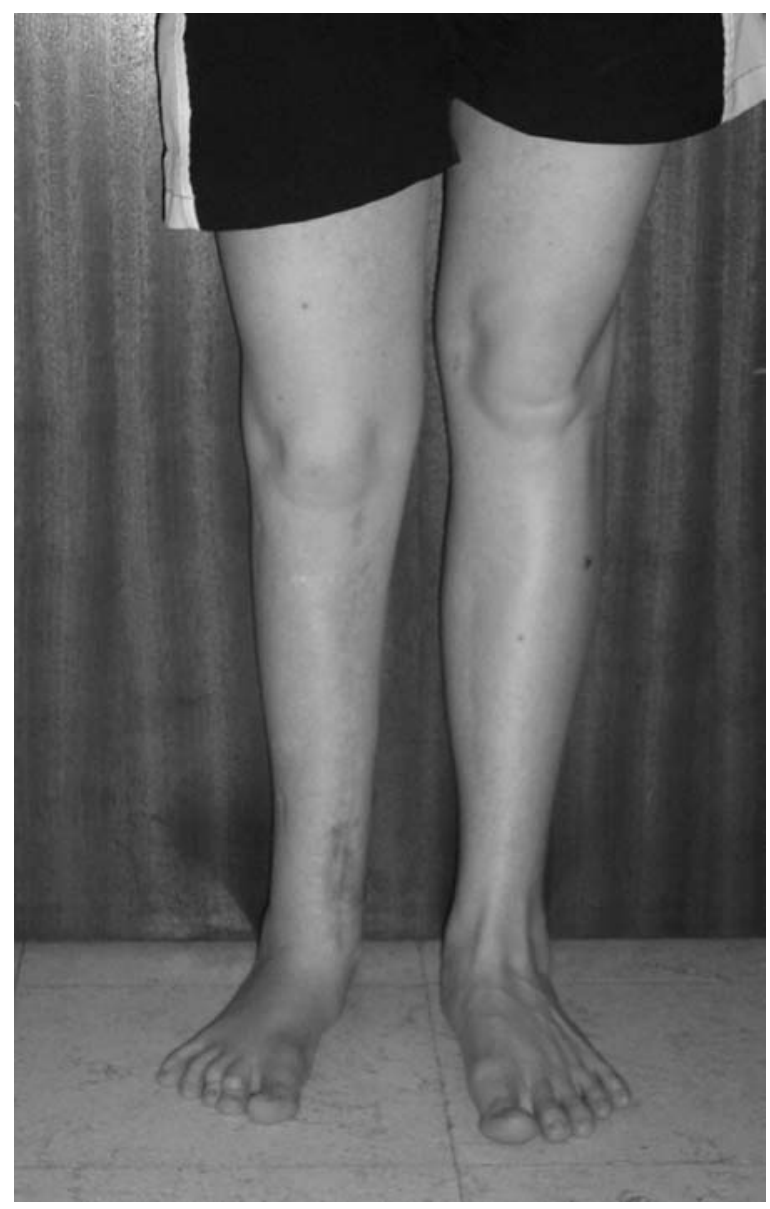

Fig. 5

Clinical appearance of the limb.

was not achieved and the bone ends became tapered and sclerotic. After two further failures using the Ilizarov technique, amputation was advised. This was refused by the family.

On referral to our hospital an alternative option was investigated. We were aware of several challenging cases of pseudarthrosis which were successfully treated using BMP7. ${ }^{6}$ Although all were adults and none had neurofibromatosis, it was decided, with parental approval, to attempt that treatment.

At the time, there was $50^{\circ}$ of anterior angulation and a $20^{\circ}$ varus deformity at the pseudarthrosis (Fig. 1), which was mobile. The ankle had only $15^{\circ}$ of plantar flexion and no dorsiflexion. The child had local pain and the leg was shortened by about $4.0 \mathrm{~cm}$.

After resection of the pseudarthrosis, intramedullary nailing and grafting were performed. A mixture of one vial of Osigraft (Stryker Biotech, Hopkinton, Massachusetts) containing $3.5 \mathrm{mg}$ of human recombinant Osteogenic pro- tein 1 (eptotermin alfa) with $1 \mathrm{~g}$ of purified collagen matrix and cancellous bone from the ipsilateral posterior iliac crest was packed into the nonunion. Because of the location of the pseudarthrosis two rods were not enough for mechanical stability. The fixation was completed by three further 2-mm K-wires and the wound closed without drainage. The leg was immobilised in a plaster cast for six months, with partial weight-bearing allowed three months after operation.

Bony union was noted five weeks after surgery (Fig. 2). The transarticular pins were removed at five months when the patient was allowed full weight-bearing (Fig. 3). Although he had no pain, walking was limited to less than one hour per day for one month and thereafter was not restricted.

The fracture was united at 28 months (Fig. 4) and the new bone appeared of good quality. Ankle mobility was unchanged. The patient had no complaints, other than minor concern about the appearance of the leg (Fig. 5). The leg was $5 \mathrm{~cm}$ shorter and he walked unrestrictedly with a 4 $\mathrm{cm}$ shoe raise. He had a good school record but did not participate in sport except cycling for a few hours a week. He and his family are very satisfied with the result.

\section{Discussion}

To our knowledge, this is the first use of BMP-7 (OP-1) for tibial pseudarthrosis associated with neurofibromatosis in a growing child.

The recognised indication for BMP-7 (Osigraft) in the tibia is for long standing post-traumatic pseudarthrosis in skeletally mature patients when autograft has failed or is unfeasible. We decided to use BMP-7 in our 13-year old patient because all other treatments had failed and the attending surgeon recommended amputation.

No benefits in any form have been received or will be received from a commercial party related directly or indirectly to the subject of this article.

\section{References}

1. Heikkinen ES, Poyhonen MH, Kinnunen PK, Seppänen UI. Congenital pseudarthrosis of the tibia: treatment and outcome at skeletal maturity in 10 children. Acta Orthop Scand 1999;70:275-82

2. Anderson DJ, Schoenecker PL, Sheridan JJ, Rich MM. Use of an intramedullary rod for the treatment of congenital pseudarthrosis of the tibia. J Bone Joint Surg [Am] 1992;74-A:161-8.

3. Boyd HB, Sage FP. Congenital pseudarthrosis of the tibia. J Bone Joint Surg [Am] 1958;40-A:1245-70.

4. Grill F, Bollini G, Dungl P, et al. Treatment approaches for congenital pseudarthrosis of tibia: results of the EPOS multicenter study. J Pediatr Orthop B 2000;9:75-89.

5. Ilizarov GA, Gravecha VI. Bloodless treatment of congenital pseudarthrosis of the crus with simultaneous elimination using dosed distraction. Orthop Traumatol Protez 1971;32:42-6 (in Russian).

6. Friedlander GE, Perry CR, Cole JD, et al. Osteogenic protein-1 (bone morphogenetic protein-7) in the treatment of tibial nonunions: a prospective, randomized trial comparing rhOP-1 with fresh bone autograft. J Bone Joint Surg [Am]2001;83-A(Suppl 1):151.

7. Cook SD, Salkeld SL, Brinker MR, Wolfe MW, Rueger DC. Use of an osteoinductive biomaterial (rhOP-1) in healing large segmental bone defects. J Orthop Trauma 1998;12:407-12. 